\title{
The Research of the Green Design and Manufacturing for the Architectural Engineering Machinery
}

\author{
J.R. Yang \\ College of Mechanical, Hunan University of Arts and Science, Changde, 415000, P.R.China
}

Yjrtt1028@sina.com

\begin{abstract}
To solve the increasingly serious resource and environmental problems, explored the method of the green design and manufacturing for the architectural engineering machinery.Researchers Researchers have made a lot of progresses in the following areas: Selection of green materials and some green manufacturing technology, modeling of green products ,disassembly design of the products and recyclable design of products. These new technology are used to improve the resource utilization rate, lower costs, reduce environmental pollution, face with the challenges of the international green trade barriers and carry out the strategy of sustainable evelopment in the for the architectural engineering machinery manufacturing.Researchers Researchers will take the Stirrup machines as study and discuss practical examples.
\end{abstract}

Keywords- Architectural Engineering; Stirrup Machines; Recyclable Design; Green Design; Green Manufacturing

\section{Introduction}

At present, many companies still go the old way that only to pay attention to the quality, cost and efficiency of the products, but to ignore the pollution to the environment from the processing using and product obsolescence. If the architectural engineering machinery would fundamentally prevent pollution, conserve resources and energy, and the key is to design and manufacture. [1] It is late to take preventive measures after the adverse environmental consequences have been produced, so before manufacturing, products and processes should be tried to prevent negative effects on the environment. This is the basic idea of green design and manufacturing in architectural engineering machinery. In this paper, based on the concept and connotation of green design and manufacturing, the green design method, the selection of green materials and some green manufacturing technology in stirrup machines were proposed.

\section{The basic concept}

Green design and manufacture in the stirrup machines is a modern manufacturing model with comprehensively consideration of environmental impacts and resource efficiency, and it is an important manifestation of the strategy of sustainable development in the manufacturing industry. It is defined as a modern design-manufacturing model with comprehensively consideration of environmental impacts and resource efficiency, and its goal is to make negative impact on the environment minimum, resource efficiency highest, economic and social benefits of enterprises coordinate optimization in the entire product life cycle from design, manufacture, packaging, transportation, using to discard processing.

\section{Method of the green design in stirrup machines}

Green design in stirrup machines is a modern design method based on the entire life cycle of the product and taking environmental resource attributes of the products as the core [2] [5].In the design, in addition to considering the product's features, performance, life and cost, the impact on the environment and resources in production, using, waste and recycling process must also be considered. It mainly includes the following respects:

A. The disassembly design of the products about stirrup machines

Researchers believe that the characteristics without disassembly will not only result in the waste of a large number of reusable parts and components but cause serious environmental pollution due to poor disposal of waste. The disassembly has become an important part of the mechanical design. As one of the main contents of the green product design, disassembly requires to be taken as an evaluation criterion of structural design in the early stages of product design. [3] [5]

\section{B. The recyclable design of products about} stirrup machines

Recyclable design is to take full account of some issues relating to the recoverability such as recycling possibility, recycling value, recycling method, recycling structural process in the early stage of product design to eventually obtain the largest use of resources and energy of the parts and materials and a minimum of environmental pollution. There are the following aspects in the recyclable design: (a) recyclable materials and signs; (b) recyclable processes and methods; (c) recyclable economy evaluation; (d) recyclable structural design.

\section{The modeling of green products about stirrup machines}

The creating a system evaluation model of green product is the key of green design. For example, in the 
process of designing the parts of a reducer, the multi-objective fuzzy optimization design is used to make the weight the lightest, the volume the smallest, the timber and the energy consumption the least [2]. Now the evaluation index system of green product and the formulation principles of the evaluation criteria have been proposed, the fuzzy evaluation method was used to evaluate the "greenness", and the corresponding evaluation tools was developed.

\section{The cost analysis of green products about stirrup machines}

Because the performance such as product recycling and re-use must be considered in the early stage of product design, researchers should take into account of the alternative of pollutants, disassembly, re-use cost, corresponding environmental cost of special products in the cost analysis. Whether an enterprise expenditures environmental costs, there would exits the difference of the product cost, and the same environmental projects in actual costs between countries or regions would also form the cost differences. Therefore, each design decision should do cost analysis on green products in order to design the product with higher "green level" and lower total costs.

\section{E. Performance design of the product resource about stirrup machines}

The main contents of the design are: (a) the model establishment of the resource consumption in the product life cycle; (b) the characteristics analysis of resource consumption in the production process.

\section{F. Green design of the hydraulic system about} stirrup machines

The hydraulic system in the common Architectural engineering machinery is a major factor of the impact on the environment whose influences are: working medium pollution on the environment due to the leakage, noise harmful to the environment, the destruction of natural resources because of energy costs [3]. The main fault of the hydraulic system in the stirrup machines is leak. The reasons are: one is sealed badly; one is the damage to the hydraulic components. Leak causes the resource waste and environmental pollution. Poor lubrication increases the wear of equipments and affects the useful life and work performance of equipments. The best way for the leakage is to improve the sealing technology such as the seal structure during designing and the process during manufacturing. The main reason for damaging the hydraulic components is the dirty of the hydraulic oil. The pollutants of hydraulic oil in stirrup machines are divided into the assembly pollutants, the invasion ones and the generated ones. [6] [7] The assembly pollutants mainly produce in manufacturing, assembly and debugging process in the factory. The invasion pollutants and the generated ones arise from the use process, which depend on the working environment of the stirrup machines, maintenance and maintenance. For this reason, parameters and structure of the hydraulic components in the design phase should be a reasonable choice to improve the sealing effect.

G. Structural design of the product about
stirrup machines
In addition to satisfying the basic requirements of ordinary products, green products mainly consider the ease of disassembly and recycling of the structure. Disassembly is the premise of the waste recycling and the recycling is the guarantee of the re-use of waste materials. The research of the structural design includes: (a) the research of the design method on product disassembly; (b) the establishment of disassembly evaluation index system; (c) the division of the disassembly structural module and its structural design; (d) the research of the recovery process and method; (e) the performance design on the product environmental.

\section{Choice of green materials in stirrup machines}

Materials are the basis constituting the stirrup machines. Now an important development direction of the green Architectural engineering machinery is that the use proportion of green materials continues to increase. Green materials, also known as environmental coordination materials or eco-materials, have good use performance or functionality, less consumption to resource and energy, less pollution on ecology and environment, benefit to human health, high recycling rate or biodegradable recycling. It can coexist with environmental coordination in the whole process from preparation, use and disposal to regeneration recycling.

\section{Manufacturing method of green machinery in stirrup machines}

Green manufacturing technology is the modern manufacturing model with comprehensive consideration of environmental impact and resource efficiency under the premise of guarantee the product's features, quality and cost. It enables the product to economize resources and energy and to do not produce environmental pollution or to minimize environmental pollution in the entire product life cycle from the design, manufacture, use to the scrapped. Environmentally friendly manufacturing technology is to minimize environmental pollution and create a safe and comfortable working environment in the manufacturing process, and its contents include reducing waste generation, waste emissions, the generation of toxic and hazardous substances, properly handling toxic and hazardous substances, lessening vibration and noise, regulating temperature and air purification, recycling and reusing of waste. The following briefly describes some green manufacturing technology:

\section{A. Precision forming process about stirrup machines}

Precision forming process, also known as little chip processing, can get parts or fine blanks by mainly utilizing some processing methods, such as the casting, forging, cold extrusion and powder metallurgy. It has significant technical and economic benefits that can achieve a variety of cold and hot process and a variety of composite materials for selection, and combine organically materials and technology, so it is a breakthrough in mechanical manufacturing technology. 


\section{B. High-speed cutting machine tools about stirrup machines}

It is well known that the dry machining in the cutting area will generate a lot of cutting heat, and if the heat is not timely distributed, the machine would be unevenly heated and produce thermal deformation, which is an important factor on the process precision. Therefore, the machine should install cycle cooling system to get away cutting heat, and own good insulation in the structure.

\section{Greening on architectural engineering machinery about stirrup machines}

For achieving the greening on the life cycle of Architectural engineering machinery, it is essential to implement green use in architectural engineering machinery.

\section{Greening on the work environment about stirrup machines}

Work environment design is to research how to provide workers with a safe, comfortable and pleasant environment. The work environment with comfortable and pleasant includes large work space, the natural and orderly layout on the work surface, moderate workplace temperature and humidity, smooth and fresh air, no obvious vibration and noise, the appropriate position of various control agencies and the operating handle and good working lighting. If a variety of lighting system of machine tool in machinery manufacturing are designed to be adjustable, which lighting power is big when loading and unloading and it is small when cutting, so it can not only guarantee the good working lighting but economize energy.

\section{Conclusion}

Green design and manufacture in architectural engineering machinery (for example about stirrup machines ) is an important part of sustainable human development strategy, and should be also a key consideration to every enterprise. The rise and development of green products is the irreversible trend, and is the tremendous progress of solving the environment, resources and sustainable development. It will have a profound impact on the future of mankind's survival and development.

\section{Acknowledgments}

This research is supported by Industrialization Development Project of Technological Achievements of Universities in Hunan Province (15CY008), the grant of the 12th Five-Year Plan for the construct program of the key discipline (Mechanical Design and Theory) in Hunan province (XJF2011[76]), Cooperative Demonstration Base of Universities in Hunan, "R \& D and Industrialization of Rock Drilling Machines" (XJT [2014] 239), the Scientific research projects (The reserch of the green design theory and means for construction machinery and equipment facing disassembing and recycling) (XBT2014-34-14YB03]);

\section{References}

[1] Zhifeng Liu, Di Hu and Li Bingbing. Model and Solution to the Product Disassembly, Sequence Planning[J]. International Journal of Environmental Technology and Management,2012, 14(5-6): 501 515

[2] Liu Zhifeng, Gao Yang, Hu Di, Ling Bo.Dishwasher's environmental impact analysis and improvement by addressing EUP directive in China dishwasher manufactures [J]International journal of Environmental Technology and Management, 2013, 15(1):61-78

[3] JiRong Yang, Yuehua Cai, Weiyue Xiao, Solving Method of Dimension Chain Based on Scientific Error Analysis Package[J]., Advances in Intelligent and Soft Computing ,2011, 104, 291-296

[4] Gao Yang, Liu Zhifeng, Hu Di, Zhang Lei. Selection of green product design scheme based on multi-attribute decision-making method [J]. International Journal of Sustainable Engineering. 2012, 3(4): 277-291

[5] Liu Zhifeng, Gao Yang, Zhang Lei, Hu Di. Green innovation design based on TRIZ theory[C]. International Conference on Advanced Design and Manufacturing Engineering, Guangzhou, China, 2011, Vol 373-379: 308-310.

[6] J.R.Yang, Q.Y.Liu, The green design and manufacturing technology based on the recycling theory $[\mathrm{J}]$. Machine Design And Manufacturing Engineering II Part 1,p541-544

[7] Liu Guangfu, Liu Zhifeng, Li Gang. Green design and green manufacture [M]. Beijing: China Machine Press, 2011.

[8] Zheng Hualin, Liu Qingyou, Zhang Jinwei, et al. Green manufacturing technology for sustainable development of manufacturing industry and strategy of implementation $[\mathrm{J}]$. Machinery, 2009(6): 49-51

[9] Liu xuepin. Studies analyzing the basic theory of mechanical and electrical products and recycling of demolition assessment methods: [J]. Machinery, 2012(11): 39-41

[10] Xu binshi , Progress and development trend of green remanufacturing engineering $[\mathrm{J}]$. Science Technology and Engineering,2011,1(1):24-29

[11] J.R.Yang, The Green Design and Manufacturing Technology Based on the Recycling Theory [J], Machine Design and Manufacturing Engineering II Part 1, 2013,541-544 